\title{
Expression of Concern: Genetic Diversity Among Historical Olive (Olea europaea L.) Genotypes from Southern Anatolia Based on SSR Markers
}

\author{
Ebru Sakar ${ }^{1} \cdot$ Hulya Unver $^{2} \cdot$ Sezai Ercisli ${ }^{3}$ \\ Published online: 29 May 2019 \\ (C) Springer Science+Business Media, LLC, part of Springer Nature 2019
}

The Editor-in-Chief and the publisher are issuing an editorial expression of concern because the validity of the content of this article (Sakar et al. 2016) cannot be verified. There is strong reason to believe that the peer review process was compromised. Investigation into these concerns could neither be confirmed nor be refuted. All authors disagree with the Expression of Concern.

\section{Reference}

Sakar E, Unver H, Ercisli S (2016) Biochem Genet 54:842. https://doi.org/10.1007/s10528-016-9761-x

Publisher's Note Springer Nature remains neutral with regard to jurisdictional claims in published maps and institutional affiliations.

The online version of the original article can be found under https://doi.org/10.1007/s10528-0169761-X

\section{Hulya Unver}

hulyaunver@hotmail.com

1 Department of Horticulture, Agricultural Faculty, Harran University, Sanliurfa, Turkey

2 Faculty of Agriculture and Natural Science, Duzce University, Duzce, Turkey

3 Department of Horticulture, Agricultural Faculty, Ataturk University, Erzurum, Turkey 